\title{
Gastroesophageal Junction Neuroendocrine Carcinoma
}

National Cancer Institute

\section{Source}

National Cancer Institute. Gastroesophageal Junction Neuroendocrine Carcinoma. NCI

Thesaurus. Code C126324.

An aggressive, high-grade and poorly differentiated carcinoma with neuroendocrine differentiation that arises from the gastroesophageal junction. According to the size of the malignant cells, the prominence of the nucleoli, and the amount of cytoplasm, it is classified either as small or large cell neuroendocrine carcinoma. 